\author{
Ewan C. Goligher \\ Franco Laghi \\ Michael E. Detsky \\ Paulina Farias \\ Alistair Murray \\ Deborah Brace \\ Laurent J. Brochard \\ Steffen-Sebastien Bolz \\ Gordon D. Rubenfeld \\ Brian P. Kavanagh \\ Niall D. Ferguson
}

\section{Erratum to: Measuring diaphragm thickness with ultrasound in mechanically ventilated patients: feasibility, reproducibility and validity}

Published online: 7 March 2015

(C) Springer-Verlag Berlin Heidelberg and ESICM 2015

The online version of the original article can be found under doi:10.1007/s00134-015-3687-3.

E. C. Goligher · M. E. Detsky · L. J. Brochard ·

G. D. Rubenfeld · B. P. Kavanagh · N. D. Ferguson (-)

Interdepartmental Division of Critical Care Medicine, University of

Toronto, Toronto, Canada

e-mail: n.ferguson@utoronto.ca

E. C. Goligher

e-mail: ewan.goligher@mail.utoronto.ca

E. C. Goligher · P. Farias · A. Murray · D. Brace · N. D. Ferguson Division of Respirology, Department of Medicine, University

Health Network, Toronto, Canada

E. C. Goligher · S.-S. Bolz · B. P. Kavanagh · N. D. Ferguson Department of Physiology, University of Toronto, Toronto, Canada

F. Laghi

Department of Medicine, Stritch School of Medicine, Edward

Hines Jr. VAH and Loyola University Chicago, Hines, IL, USA

M. E. Detsky

Department of Medicine, Mount Sinai Hospital, Toronto, Canada

L. J. Brochard

Keenan Research Centre for Biomedical Science, St. Michael's Hospital, Toronto, Canada

\section{G. D. Rubenfeld}

Department of Critical Care Medicine, Sunnybrook Health Sciences Centre, Toronto, Canada

B. P. Kavanagh

Department of Anesthesia, University of Toronto, Toronto, Canada

B. P. Kavanagh

Department of Critical Care Medicine, Sick Children's Hospital, Toronto, Canada

G. D. Rubenfeld · N. D. Ferguson

Institute for Health Policy, Management and Evaluation, University of Toronto, Toronto, Canada

N. D. Ferguson

Toronto General Research Institute, Toronto, Canada

N. D. Ferguson

Toronto General Hospital, 585 University Avenue, 11-PMB-120, Toronto, ON M5G 2N2, Canada

\section{Erratum to: Intensive Care Med DOI 10.1007/s00134-015-3687-3}

Owing to an oversight, the name of the eighth author of this article was rendered wrongly. His correct name is Steffen-Sebastien Bolz. 